\title{
E-learning in Business Practice, a Case Study During COVID-19 in Croatia
}

Dominika Crnjac Milić, Zdravko Krpić and Filip Sušac

J. J. Strossmayer University of Osijek, Faculty of Electrical Engineering

Computer Science and Information Technology Osijek, Kneza Trpimira 2b, 31000 Osijek, Croatia

E-mail: dominika.crnjac@ferit.hr, zdravko.krpic@ferit.hr, filip.susac@ferit.hr

Keywords: business practice, COVID-19, Croatia, e-learning, employee education

Received: July 31, 2020

\begin{abstract}
Technological progress is increasingly changing the form of learning and communication in the business environment. The omnipresence of computers enables distance learning to an increasing number of people, whose systematic use is enabled primarily via various e-learning platforms. To be a market competitive, companies must be ready for fast changes and constant adaption to the new technologies. This paper provides a brief classification of e-learning its features and its content as well as an overview of the presence of e-learning in the companies from the Republic of Croatia via a survey that we conducted among 80 of them. The results of the survey are particularly important since they were collected during the COVID-19 pandemic when companies were abruptly forced to adapt to working from home. The primary goal of the survey was to analyze to which extent they use e-learning for their daily business and education of the employees. The survey also shows what services do they use and prefer the most and what is their overall opinion about e-learning in business.
\end{abstract}

Povzetek: V prispevku je analizirano e-učenje v 80 hrvaških podjetjih za časa krize COVID-19.

\section{Introduction}

Nowadays, running a competitive business organization considerably depends on the ability to adapt to the new technologies and working conditions. Investing in employees in terms of learning and mastering new skills results in greater productivity and better time management [1]. This is especially evident during crises, such as an ongoing COVID-19 pandemic, which is one of the biggest that humanity saw in recent history [2].

In this paper, we aim to capture aspects of e-learning in the business sector, such as the expected benefits from it, frequency of its use, technologies utilized, and the general opinion of its users and company managers. These aspects are rather important considering that they were collected during the COVID-19 pandemic, which acts as a stress test for the companies' ability to embrace elearning in their businesses. We collected the most important information about the use of e-learning and investing in employee education, via a survey conducted among 80 Croatian companies.

There are numerous advantages of utilizing e-learning in business practice, starting from the possibility of educating employees at any place at any time, intensified mutual interaction, and significant savings in time and money invested in employee education [3]. Via a survey, we analyzed if the Croatian companies recognize the importance of e-learning and whether they utilize its full potential.

One set of questions within the survey was designed specifically to evaluate the importance and frequency of use for various types of content present within the e- learning platforms that participants use, as well as to identify the challenges that may arise during their use. To put the collected answers into context, we provided an overview of the advantages and disadvantages of elearning beforehand, as well as their classification. This way we give a good estimate of e-learning options available to the users today. Thus, this paper aimed to provide theoretical and empirical background on elearning and verify it by the Croatian business practice use case.

This paper is organized as follows. In Section 2., a general overview and classification of the e-learning is presented. Section 3. describes the survey conducted among companies in Croatia, whereas Section 4. provides the analysis of the survey. Section 5. concludes the paper with recommendations for the inclusion of e-learning in businesses.

\section{The overview of e-learning}

Planning, design, development, implementation, and control of an e-learning system are a serious undertaking, regardless of the degree of knowledge of all methodological and technological aspects. Respecting the fact that technologies are developing at astonishing speed and that the access to employee education is often exposed to changes, there is a great potential for failures that needs to be minimized, such as dropouts and insufficient technical knowledge [4]. According to [5], today's elearning systems can be classified into six main types, as shown in Table 1 . In practice, there is a rising trend on 
hybrid teaching and online education, which are a part of distance learning. E-learning continuum is given in Figure $1[6]$.

E-learning has several definitions, but the most general one is that e-learning is a learning method that uses

\begin{tabular}{|l|l|}
\hline Type of e-learning & Description \\
\hline face-to-face, F2F & $\begin{array}{l}\text { e-learning with physical presence } \\
\text { and without e-communication }\end{array}$ \\
\hline self-learning & $\begin{array}{l}\text { e-learning without presence and } \\
\text { without e-communication }\end{array}$ \\
\hline asynchronous & $\begin{array}{l}\text { e-learning without presence and } \\
\text { with e-communication }\end{array}$ \\
\hline synchronous & $\begin{array}{l}\text { e-learning with virtual presence } \\
\text { and with e-communication }\end{array}$ \\
\hline blended/hybrid-asynchronous & $\begin{array}{l}\text { e-learning with occasional } \\
\text { presence and with e- } \\
\text { communication }\end{array}$ \\
\hline blended/hybrid-synchronous & $\begin{array}{l}\text { e-learning with presence and with } \\
\text { e-communication }\end{array}$ \\
\hline
\end{tabular}

Table 1: Types of e-learning.

ICT to ubiquitously transform and support teaching and learning process [7]. According to [8], in e-learning participants receive knowledge via the Internet without having to physically be present where the education takes place. Recently, multimedia is progressively more used to improve learning, with a high emphasis on IoT systems.

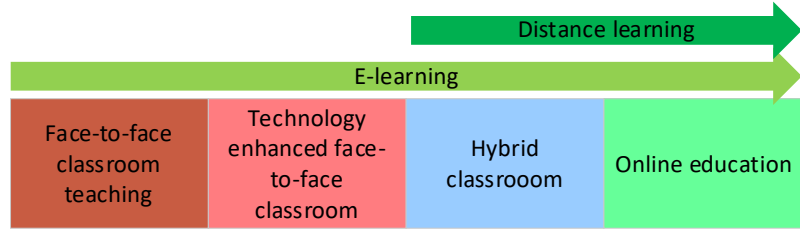

Figure 1: Continuum of e-learning.

In the last decade, the e-learning platforms proliferated due to the increased interest in e-learning. Elearning platforms are web sites that encompass diverse content and high-quality learning opportunities. They enable communication between lecturers and participants, as well as between the participants (or lecturers) themselves. According to [7], e-learning platforms include visualization, animation, simulations, various interactive elements, tests, quizzes, forums, distribution lists, and other types of content. Therefore, preparation for the online execution of one teaching unit is usually a lot more challenging than for the off-line execution. One set of questions within the survey was designed specifically to evaluate the importance and frequency of use for various types of content present within the e-learning platforms that participants use, as well as to identify the challenges that may arise during their use. In order to put the collected answers into context, we provided an overview of the advantages and disadvantages of e-learning beforehand, as well as their classification. This way we give a good estimate of e-learning options available to the users today. Thus, the aim of this paper was to provide theoretical and empirical background on e-learning and verify it by the Croatian business practice use case.

\subsection{Advantages and disadvantages of the e- learning}

There are several reasons why it may be justifiable to develop an online education system for different kinds of courses [9]. For academic purposes, these reasons are the ability to create an online school subject, a college course, or some other kind of a course, as well it contributes to the development of the basic skills needed for lifelong learning [10]. For companies, e-learning is a way to provide lifelong learning, to enable working from a distant location or to upgrade employee skills required for daily tasks. According to [11], users are learning faster by elearning than by $\mathrm{F} 2 \mathrm{~F}$ learning, thus making e-learning as a possible answer to the increasingly challenging demands of the business market and society. Some of the identified benefits of e-learning are:

- Possibility of learning anywhere

- Possibility of learning anytime

- Mutual synergy between lectures and participants

- Participants are in the center of attention

- No discrimination

- Creative learning

- Greater access to resources

- Simplified feedback

- Tailoring one's own education

However, e-learning has also some negative aspects that are still not completely remedied in practice and therefore can reduce productivity and the amount of knowledge transferred. One of them is considered to be the lack of communication between the participants, which was shown to be the main reason for the participant dropout, [12]. In [13] the authors have shown that most respondents believe e-learning can help in developing new skills. But most of them, at the same time, feel that they have insufficient knowledge and experience to take a full advantage of the benefits of e-learning. Additionally, they believe that newer generations are more likely to accept elearning, considering that they grew up with computers and mobile phones, unlike older generations. This realization points to the need that the e-learning content in the business sector must be more contextual and dynamic than in a classical academic or school environment. It is also necessary to encourage interaction among the participants of e-learning so that they do not feel isolated, and to be additionally motivated by receiving feedback from other participants on the acquired knowledge. Some other identified disadvantages of e-learning are:

- Obligatory access to the computer

- The necessary basic knowledge of using computer

- Insecurity of technology

- Social isolation

- Creating technology addiction

- Lack of self-discipline of education participants

- Too many participants to achieve optimal synergy

- Not all content is suitable for online education 
- The need to maintain and introduce innovations due to new technologies and modern content in distance education

- Inability to transform the traditional curriculum into online education

Another view on the advantages and disadvantages of e-learning, given from the medical perspective is available in [14]. Some of the advantages and disadvantages emerge also from the results of the survey given in Section 4.

\subsection{E-learning classification}

According to [15], e-learning can be classified according to:

- Type of the platform on which it is taking place

- Application area

- Standard

- Type of learning

- Type of tools that the platform can have

- Type of activity

The list of e-learning types for each classification is given in Figure 2.

\subsubsection{Classification according to the type of platform}

Considering the type of the e-learning platform, the three types exist:

- Learning Management System (LMS) - most often used in both the business sector and in higher education. It is a platform that allows one to store and deliver learning content and to monitor the user's participation. The main goal of LMS is participant management and monitoring their activity [9]. In essence, LMS is an automated software for tracking, reporting, administration, registration, and evaluation [16].

- Learning Content Management System (LCMS) - primarily used for creating, storing, and organizing content. Unlike LMS, it is used to create learning content and publish it in various forms. It can be perceived as an upgraded version

\begin{tabular}{|c|c|c|}
\hline By type of platfom & By application area & By standard \\
\hline $\begin{array}{c}\text { Learning Management } \\
\text { System }\end{array}$ & Business Sector & $\begin{array}{c}\text { Sharable Content Object } \\
\text { Reference Mode }\end{array}$ \\
\hline $\begin{array}{c}\text { Learning Content } \\
\text { Management System }\end{array}$ & School Institutions & $\begin{array}{c}\text { Tin Can Application } \\
\text { Program Interface }\end{array}$ \\
\hline $\begin{array}{c}\text { Content Management } \\
\text { System }\end{array}$ & \\
\hline
\end{tabular}

of LMS with some content management features [9].

- Content Management System (CMS) - unlike LMS and LCMS, it is based mostly on content, and its quick and efficient use. CMSs enable creating online courses, uploading documents and presentations in various formats and other content features [16]. CMSs specialize in the creation and management of learning content.

\subsubsection{Classification according to the application area}

Classification according to the application area divides the platforms into two groups:

- The business sector - the aim is to enable employees to acquire knowledge and skills to increase their competence for work and for executing the specific tasks that are put before them. The main features of the e-learning in the business sector are a fast pace, heavy focus on the task for which education is intended, and the emphasis on achieving maximum results.

- Academic institutions - unlike in the business sector, the main goal is to transfer different aspects of knowledge rather than to train participants to perform certain tasks. According to [17] $99 \%$ of the high education institutions have an LMS in place, where $85 \%$ of them have been utilized to support their educational services. Although the primary task of e-learning in the academic sector is to improve the educational process, students also gain overall knowledge about e-learning which then serves as a base for further improvement of knowledge and skills.

\subsubsection{Classification according to standard}

Two types of e-learning platforms exist according to elearning standards:

- Sharable Content Object Reference Mode (SCORM) - an older standard that is slowly being

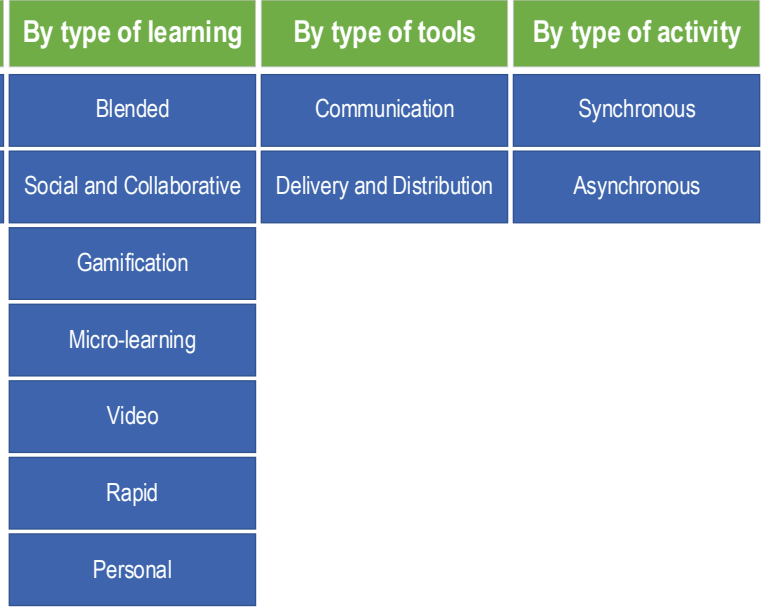

Figure 2: Classification of e-learning. 
replaced by Tin Can API. Both standards allow users to run the course, take quizzes, monitor user's work. Still, SCORM is simpler and has fewer options.

- Tin Can Application Program Interface (Tin Can API) - although similar to the SCORM standard, is increasingly being used since it is more reliable, it makes it easier to handle a large number of data, it enables better tracking of the user's work and the most important part is that it is still being upgraded and will be even more advanced in the future.

\subsubsection{Classification according to the type of learning}

Classification according to the type of learning split elearning platforms into seven main groups:

- Blended learning - a combination of F2F learning and online learning in a way that the one complements the other. It is also called hybrid learning.

- Social and collaborative learning - learners work together to expand their knowledge of a subject or skill. It is typically done through live chats, message boards, or instant messaging.

- Gamification - the use of game-based mechanics, and game thinking to engage people, promote learning, and solve problems. Games are created to draw people in, to keep them playing, to keep them interested and involved.

- Micro-learning approach - can provide educational benefits without overwhelming the learner. It is quickly becoming one of the most popular e-learning trends.

- Video learning - brings a whole new dimension to the teaching methods because of the theory that everything that is being taught can be demonstrated. Video also helps to add a feeling of personalization to a course. A video of the tutor giving a lecture helps the students to feel a connection.

- Rapid e-learning - essentially a faster process of designing and developing online-based learning courses. Rather than spending months, rapid elearning allows creators to build lessons and content in a matter of days or weeks. Typically, this is done through PowerPoint or narrated videos and after that, a software is utilized to evaluate the students, as well as to provide them with activities that they can perform on their own in between presentations or videos.

- Personalized e-learning - enables participants to customize a variety of the elements involved in the online education process. This means that they are asked to set their own goals, go at their own pace, and communicate with instructors and participants to personalize the learning process. The most important thing is the feedback that improves learning results.

\subsubsection{Classification according to the tools that a platform can have}

This classification identifies two main groups of elearning platforms:

- Communication tools - which include blogs, Email, instant messaging, online groups, chats, forums, and web-conferencing.

- Delivery and distribution tools - which include websites, sharing files, and streaming.

\subsubsection{Classification according to the type of activity during e-learning}

Classification according to the type of activity performed during e-learnings results in two main groups of e-learning platforms:

- Synchronous activities - real-time activities such as web conferencing, instant messaging, and chats. The problem with synchronous activities is that the activities are not time-flexible, and the user must be online at that time when they are running.

- Asynchronous activities - education can be carried out even when a user or a lecturer is offline. The user can attend the education at his own pace. Examples of asynchronous activities are blogs, forums, E-mail.

The types of e-learning enumerated in this chapter show that users have a wide range of knowledge delivery methods available to them. Companies typically use the types of e-learning that offer specific knowledge of a particular area, the fastest delivery of that knowledge and that cost the least.

\section{Data collection process and survey hypotheses}

\subsection{Research methods and limitations}

To investigate the impact, importance, and presence of elearning in Croatian business practice, we conducted an online survey. The survey encompassed several types of questions. The survey was based on Google Forms and consisted of 26 questions. The types of questions included 15 questions with a single answer, 2 short text questions, and 9 multiple answer questions where participants could range their responses according to the Likert scale. One question was linked with the answer of a previous one, so not all participants had the same number of questions. The survey was distributed among participants using a direct link which was forwarded to the e-mail addresses of the targeted companies. Data were collected in a period of almost two months, from March $20^{\text {th }}$ until May $17^{\text {th }} 2020$. The target groups of this research (and survey) were company owners, CEOs, and managers as they have the most complete information about the company management.

A total of 80 companies registered in the Republic of Croatia participated in the survey. Some of the companies 
that participated in the survey are multinational, and although they are registered in the Republic of Croatia, they operate in synergy with the companies having the same owner in other countries. In addition to having different positions in the company, the participants also have different amount of work experience and were of a different gender.

The main questions of the survey were:

- How much does the use of e-learning platforms contribute to your business?

- Assess the ability of your company's employees to acquire knowledge through e-learning platforms?

- How much knowledge can be acquired through elearning platforms compared to the traditional teaching methods?

- Do you think your employees respond positively to the obligation to use e-learning platforms?

- How important is a particular form of content for the acquisition of knowledge through e-learning platforms?

The rest of the questions were used to deepen the information collected by the main questions.

This study has potential limitations. The results were obtained on a relatively small sample of companies that were willing to participate. However, we believe that the number of participating companies is big enough to give an insight into the validity of the hypotheses made within this work (due to their nature). Also, it would require a significant effort to increase the sample size considering their busyness and availability. Care was taken to ensure having a sample heterogeneous enough with regards to both size and the type of company's activity, but the results are a bit biased towards big companies. Additionally, there was no equal sampling from different economic activities, which is going to be a part of the future work.

\subsection{Research goals}

The survey was conducted throughout a two months period, during the special working conditions caused by the COVID-19 pandemic, which had a tremendous impact on incorporating new business solutions for business owners and employees in management positions. Uncertainty and increased responsibility imposed by the situation in which they found themselves, affected the need for educating the employees, the need for changes in the organization and mode of operation of the company. The realization of the necessity of using ICT in everyday business has gained another dimension. Many companies have switched their business and communication to an online form. There was also a need to educate employees online. In addition to all the above, a motivation for this research emerged with a primary goal to find out the attitude of the target group of participants towards the acquisition of new knowledge and skills of their employees via e-learning. It is important to emphasize that the participants' position and the responsibility entrusted to them in companies imply that they should be the motivators for their employees to accept new models of education (which also makes significant savings to their companies). Participant opinion about the general acceptance of the online education in their company, and what content they think is relevant for improving the productivity of their employees is one of the key information for creating a e-learning system tailored to the workers need.

According to [18] many e-learning courses are meaningless from the perspective of meeting the education goals. For example, some business organizations only want to meet some of the regulatory guidelines and show that they have provided training that is provided to employees according to standards and trends. Additionally, it has been proved useful to know the general opinion about e-learning of a selected group of participants who create added value daily through their business in the Republic of Croatia, but also abroad.

The hypotheses of our research conducted by this paper were as follows:

H1: E-learning programs in business organizations are relatively new and there is a possibility of facing increased caution and distrust of managers and employees towards the manner of e-learning, as well as the results achieved by it.

H2: By recognizing the usefulness of e-learning, companies regardless of their size implement them.

H3: E-learning is conducted in a targeted and segmented manner, with the aim of raising the overall work performance.

H4: E-learning is rarely perceived as an unnecessary burden on top of the already busy working hours, making employees aversive towards it.

\section{Survey analysis}

Great anticipation was linked with survey analysis, since they were collected during the COVID-19 pandemic, thus making them particularly relevant. Namely, during the pandemic, the e-learning platforms had peak use, which exposed all the potential drawbacks and advantages that they may have. During these times, many employees were sent to work from home, as well as were instructed to attend various online training. Also, some companies tried to turn the situation in their favor by using the idle times of their employees to enroll them into various educations, as well as to reorganize their businesses into working from home.

A total of 80 companies participated in the survey, making the results even more relevant for understanding the e-learning practices in the business sector. It is worth to mention that the anonymity of each participant was respected.

\subsection{Information about the participants}

The aim of the first three questions was to acquire information about a person who completed the survey, for a clearer understanding of the context under which the answers were given. Considering the information about the participants, their average age was 41 years, with the 


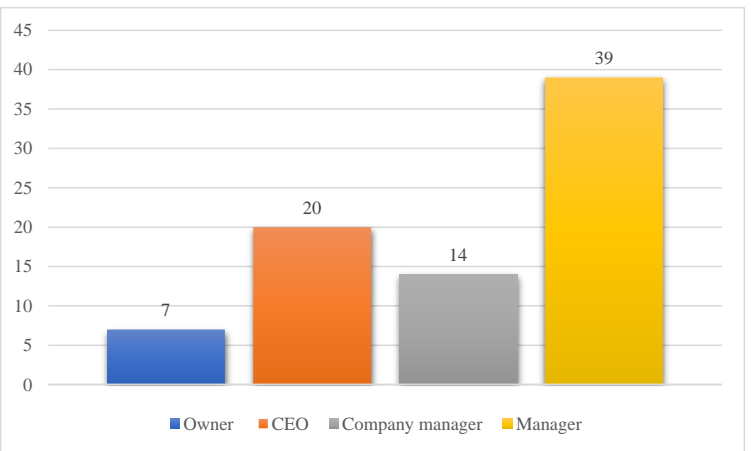

Figure 3: Number of participants for each type of the position inside a company.

oldest one being 60 and the youngest only 26. From 80 participants, 52 were women what represents $65 \%$. The participants' position in the company is shown on Figure 3.

To further back up the validity of the responses it is worth to mention that over $65 \%$ of the participants have more than 15 years of working experience, indicating that the participants are sufficiently professional and competent to be the candidates for our survey.

\subsection{Information about the companies}

The companies in Croatia classify, according to their size, into micro (less than 10 employees), small (10 to 50 employees), middle (50 to 250 employees), and big (more than 250 employees).

Figure 4a presents the shares of the company sizes in the number of participants, where it is evident that most of the participated companies are big companies with more than 250 employees. Since larger companies have a more complex organization and usually have proprietary divisions that deal with the welfare of the employees, it is expected that they care and invest more in the education of their employees. Shares of the participated companies according to their output are presented in Figure 4b. As a general trend, most of the companies surveyed are service companies, which are known to utilize ICT in their businesses more than the manufacturing companies.

\subsection{E-learning practices}

Of the companies surveyed, only $13.75 \%$ use e-learning for more than ten years, while most of them $(71.25 \%)$ use it for less than five years. This supports our first hypothesis (H1) that e-learning is fairly new in Croatian businesses. Nevertheless, one should bear in mind that the expansion of e-learning in the Republic of Croatia has only occurred in the last decade. The surveyed companies are evidence of modernizing and digitalizing of employee education. The competency of the employees in the field of ICT is vital for harnessing the benefits of e-learning. This is evident from the fact that, according to participants' opinion, $53.75 \%$ of the surveyed companies have more than $50 \%$ of employees who have the needed skills to use e-learning platforms, while only $12.5 \%$ of the companies have less than $10 \%$ of employees with those skills. Consequently, the surveyed companies form a good

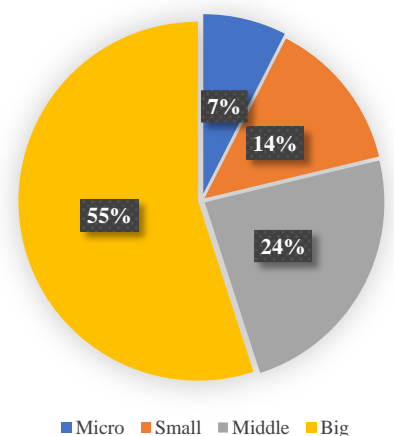

a)

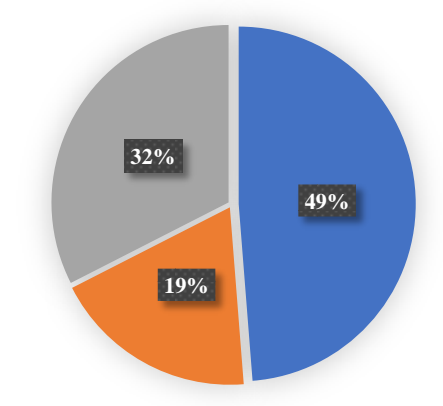

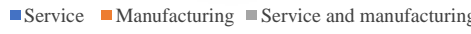

b)

Figure 4: Company classification according to a) size, b) the type of its output.

representative sample for surveying opinions on elearning. All the participants claim that their company uses the Internet or Intranet for their daily businesses. According to them, the modern business market requires workers with additional skills not obtained via formal education process, where $71 \%$ of participants answered that they completely agree, see Figure 5. This is on par with $\mathrm{H} 2$, since companies agree that e-learning is necessary and useful.

Investing in new technologies and employee education is important for each company to keep up with the market demands, [19]. A vast majority of the surveyed companies recognize that importance, considering that almost $94 \%$ of them invest in educating their employees. The frequency of investing in the education of the company's employees is shown in Figure 6. There are still companies that rarely invest in educating their employees ( $2.67 \%$ of them responded so), which can be due to different reasons.

One of the major reasons could be the fact that they consider their business do not need updating, while the second is probably that their employees are being educated elsewhere.

The frequency of investments in employee education concerning desired outcomes is shown in Figure 7. Most companies focus on investments in upgrading the skills of their employees needed for their current job and, to some extent, to prepare them for the future challenges of their workplaces. Still, most of them periodically invest in career development and education for new working skills. 


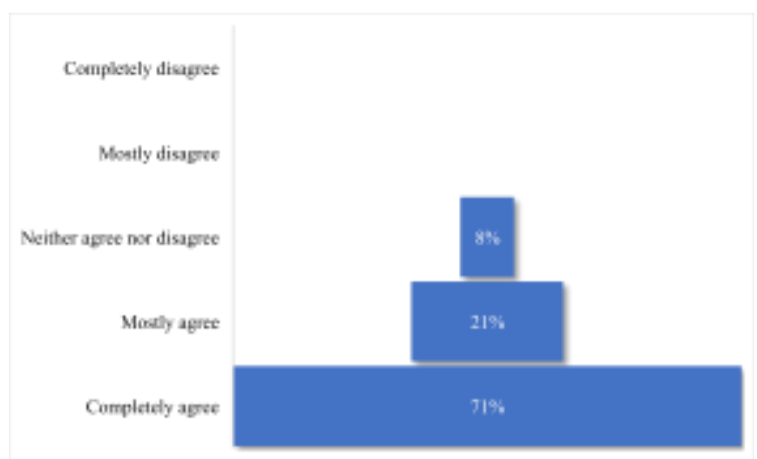

Figure 5: To which extent the participants agree that modern business market requires workers with additional skills not obtained via formal education process.

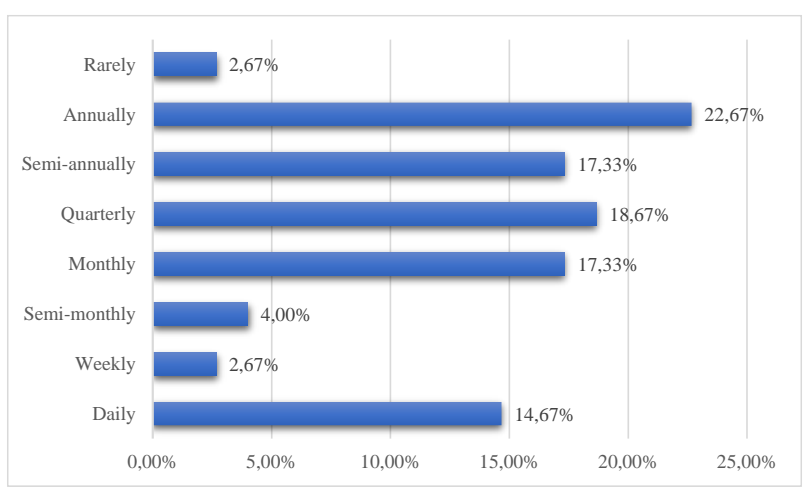

Figure 6: The frequency of investments in employee education.

The types of investments in employee education show that the companies are aware of the future challenges and try to keep up with them as much as their budget allows.

When we correlate the frequency of investing in education with the company size it is evident that smaller companies share similar habits with the big ones (Figure 8.). The only difference is that big companies avoid daily investments in education and prefer to do it annually, whereas smaller companies prefer daily investments. This supports $\mathrm{H} 2$ since it is obvious that all companies, regardless of their size, tend to invest in educating their employees. Also, the habits of investing in employee education support $\mathrm{H} 3$, since there is a clear awareness that educating employees is useful and that it will eventually pay-off.

Since bigger companies have more complex organizations and specialized divisions that deal with and plan the activities of their employees, they mostly have an elaborate plan for the education of their employees (i.e. there are no spontaneous investments into education). Smaller companies overcome the lack of planning and resources to reorganize quickly and to retrain their employees for the upcoming business demands, therefore having more frequent investments in the education of their workers.

From the survey results, it is evident that the companies recognize the importance of employee education and using the e-learning platforms. The deeper analysis of how the employee education will reflect on

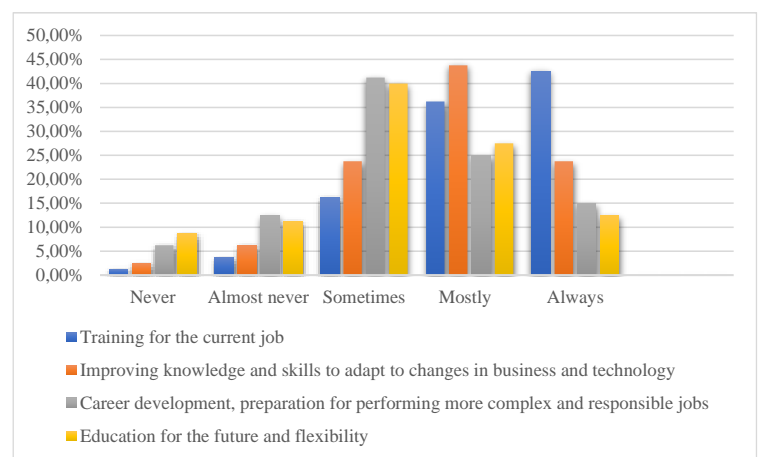

Figure 7: Frequency of investing in employee education according to the desired outputs.

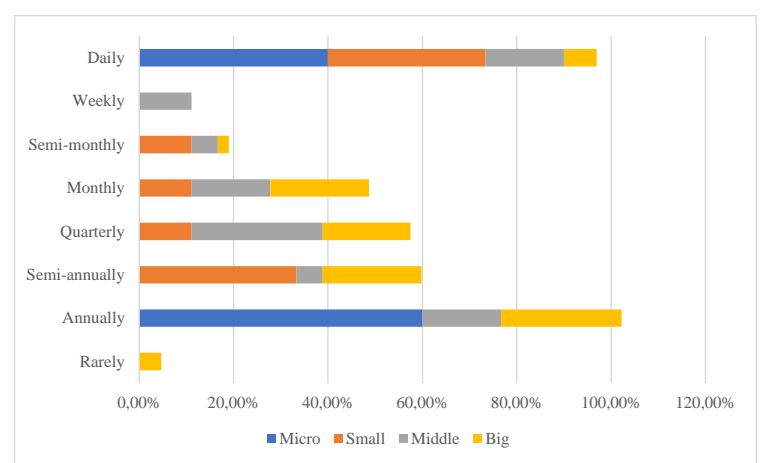

Figure 8: Frequency of investing in employee education according to the company size.

their company, extracted from the participants' opinions, is given in Table 2 .

For all the analyzed education outcomes the participants agree that the education will mostly bring benefits. This is especially evident for the claims that education improves problem-solving and that it improves controlling new and unusual situations that may arise in the company. Only one claim had the biggest variety of responses: that the education will improve customer service. This led us to conclude that participants believe more parameters are affecting the customer service, other than education (probably social skills and the like).

Most participants believe that the areas that are least likely to be improved by education are the creativity of their employees and conflict management, but this is only to a lesser extent. This supports $\mathrm{H} 3$ since most participants believe that education (served via e-learning platforms) will increase the overall work performance.

\subsection{The usage of e-learning platforms}

Analysis of the frequency of e-learning platform use shows that only a small number of employees use it for daily working tasks or education, while most employees use it only up to two hours monthly. Level of integration of e-learning in daily tasks is still at a low level, thus somewhat supporting $\mathrm{H} 1$ (e-learning being a fairly new concept to Croatian companies) and, to some extent, $\mathrm{H} 4$ (e-learning appears as an additional load on top of the usual tasks). 


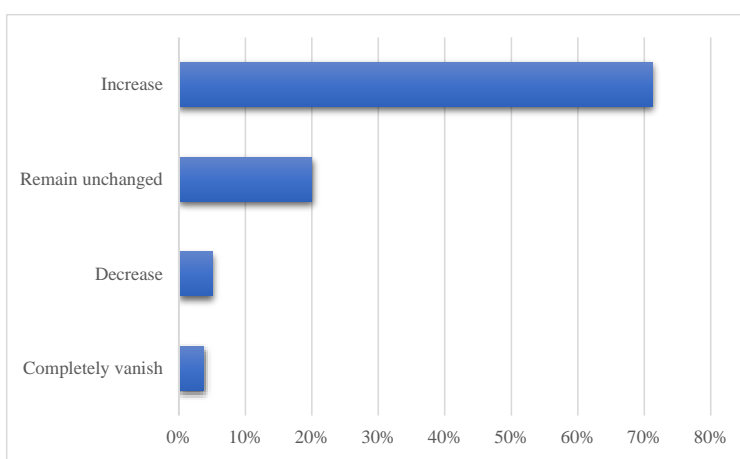

Figure 9: Participants' opinion on e-learning trend.

Finally, we asked the participants to share their projections on the future of e-learning platforms. Figure 9 gives their responses.

The results indicate that e-learning has a shiny future; it will probably be one of the basic tools used for improving businesses. At the same time, the participants do not think that e-learning is necessarily a great advantage compared to the traditional teaching methods, see Figure 10. The general opinion is that the amount of knowledge acquired is equal regardless of using either elearning or traditional teaching methods, which was the answer of $56 \%$ of the participants. Also, only a minority of participants think that the amount of knowledge acquired via e-learning is greater compared to the traditional teaching methods (18\%). Both results support $\mathrm{H} 1$, since there is still a dose of distrust towards e-learning platforms, and people still prefer the presence of teachers and other participants.

The results indicate that e-learning has a shiny future; it will probably be one of the basic tools used for improving businesses. At the same time, the participants do not think that e-learning is necessarily a great advantage compared to the traditional teaching methods, see Figure 10. The general opinion is that the amount of knowledge acquired is equal regardless of using either elearning or traditional teaching methods, which was the answer of $56 \%$ of the participants. Also, only a minority of participants think that the amount of knowledge

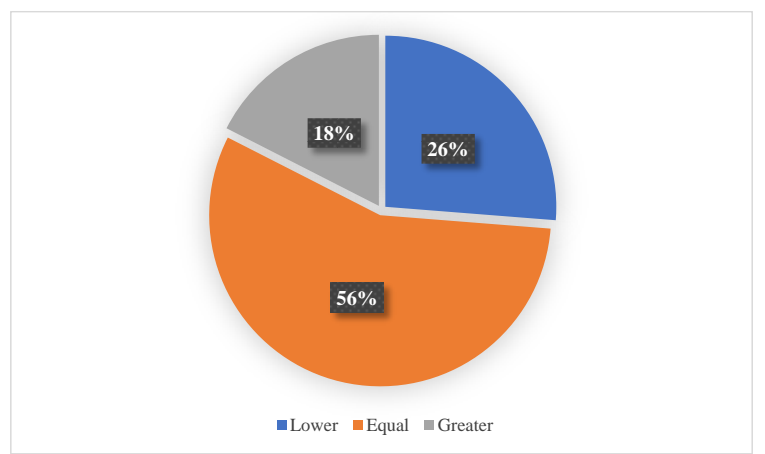

Figure 10: The participants' opinion about the difference in the amount of knowledge acquired using e-learning compared to traditional teaching methods.

acquired via e-learning is greater compared to the traditional teaching methods $(18 \%)$. Both results support $\mathrm{H} 1$, since there is still a dose of distrust towards e-learning platforms, and people still prefer the presence of teachers and other participants. New research indicate that this has solid ground, since it has been proven that the traditional way of teaching shows better knowledge transfer than via online teaching.

Content-wise, e-learning platforms are quite advanced and rich systems. Today's e-learning platforms introduce many different types of content and activities that can be used to produce, share, analyze, verify, and assess the course materials. With that in mind, we asked the participants to analyze which of these types of content and activities they find the most important for acquiring knowledge, and which ones they use the most. Regarding the intensity of use, the results show that games, quizzes, and virtual classrooms are most scarcely used, Figure 11.

Interestingly enough, those very virtual classrooms were the main means of teaching in many academic institutions during the COVID-19 pandemic. This indicates that in the business sector e-learning was used in the same way prior the pandemic and during the pandemic - more oriented towards individual learning. The content

\begin{tabular}{l|ccccc} 
& Never & Almost never & Sometimes & Mostly & Always \\
\hline $\begin{array}{l}\text { Education will improve customer service } \\
\begin{array}{l}\text { Education will contribute to change of } \\
\text { attitude }\end{array}\end{array}$ & $1.25 \%$ & $5.00 \%$ & $22.50 \%$ & $\mathbf{4 6 . 2 5 \%}$ & $25.00 \%$ \\
Education will improve teamwork & $2.50 \%$ & $7.50 \%$ & $33.75 \%$ & $\mathbf{4 2 . 5 0 \%}$ & $13.75 \%$ \\
Education will improve time management & $0.00 \%$ & $3.75 \%$ & $27.50 \%$ & $\mathbf{4 6 . 2 5 \%}$ & $22.50 \%$ \\
Education will improve work safety & $1.25 \%$ & $5.00 \%$ & $25.00 \%$ & $\mathbf{4 7 . 5 0 \%}$ & $21.25 \%$ \\
$\begin{array}{l}\text { Education will improve problem solving } \\
\text { Education will contribute to better }\end{array}$ & $1.25 \%$ & $5.00 \%$ & $28.75 \%$ & $\mathbf{5 0 . 0 0 \%}$ & $15.00 \%$ \\
handling of new tasks & $1.25 \%$ & $1.25 \%$ & $21.25 \%$ & $\mathbf{5 8 . 7 5 \%}$ & $17.50 \%$ \\
$\begin{array}{l}\text { Education will improve creativity } \\
\text { Education will improve product quality }\end{array}$ & $1.25 \%$ & $1.25 \%$ & $13.75 \%$ & $\mathbf{5 8 . 7 5 \%}$ & $25.00 \%$ \\
$\begin{array}{l}\text { Education will improve conflict } \\
\text { management }\end{array}$ & $1.25 \%$ & $3.75 \%$ & $26.25 \%$ & $\mathbf{5 1 . 2 5 \%}$ & $17.50 \%$ \\
Education will drive up to promotion & $1.25 \%$ & $5.00 \%$ & $38.75 \%$ & $\mathbf{4 1 . 2 5 \%}$ & $13.75 \%$
\end{tabular}

Table 2: Participants' opinion on how employee education will affect their companies. 


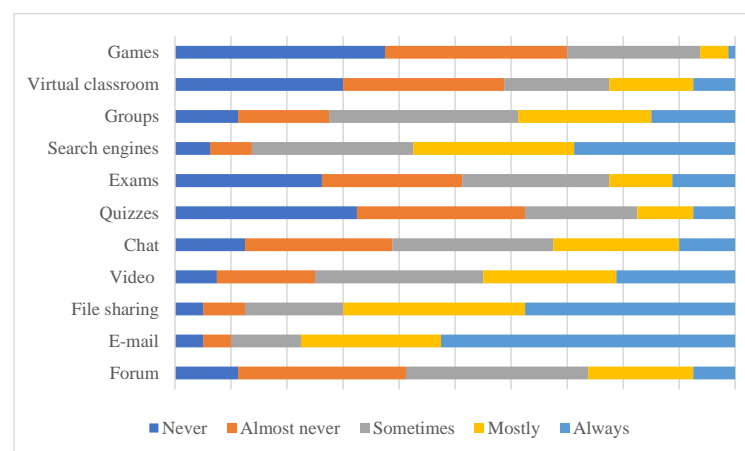

Figure 11: The frequency of using different types of elearning platform content.

types that were most often used were emails, followed by file sharing and, to a lesser extent, search engines.

The importance of different types of content and activities within e-learning platforms is given in Figure 12. The participants think that file sharing is always important, following by emails and then search engines. The participants were quite indecisive when determining the importance of forums and quizzes, although these tools are extensively used. But they are used more from the teacher's side than from the participant's side since participants use them more passively (mostly for getting short information).

Comparison of the results shown in Figure 11 and Figure 12 reveals the tight correlation between the importance and intensity of use of different activities within e-learning platforms. This means that the participants believe that the types of content they use the most is the very relevant one for acquiring knowledge, and vice-versa for the content types they use scarcely. The indication is that they are mostly satisfied with the current e-learning processes, but also that they got used to certain type of activities. This somewhat proves $\mathrm{H} 3$, since participants believe that e-learning is conducted in a targeted manner.

\section{Conclusion}

In today's dynamic times, one is not limited to the compulsory knowledge acquired by the school system, and on the other hand, employers cannot afford the routine work of their employees. It is extremely important to develop and expand knowledge and to improve and acquire new skills to keep up with new trends and create added value for one's company.

E-learning systems are a fast, reliable, and effective way of teaching which is not limited by space and time provided for teaching. In addition to saving time and reducing training costs, it enforces greater responsibility and self-discipline on participants, it enables selfevaluation of acquired knowledge and progress monitoring, thus ultimately leading to better knowledge transfer. E-learning additionally motivates students compared to the F2F learning by enabling repeated returns to the educational content over a longer period and by choosing the pace of learning adapted to their obligations. E-learning also provides a consistent and standardized approach to each education, thus allowing each participant

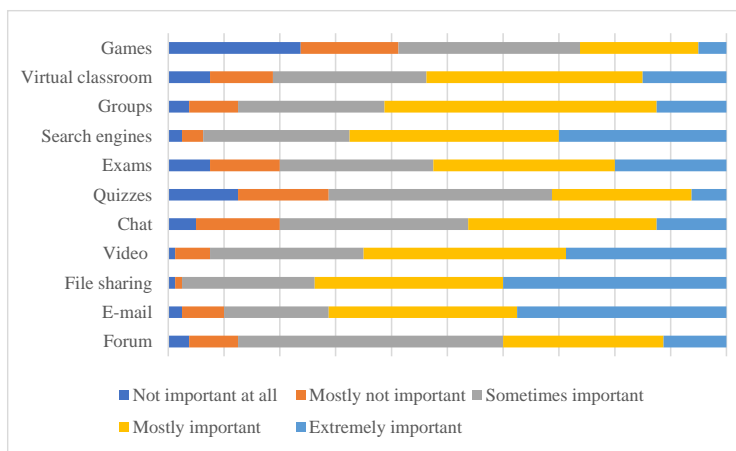

Figure 12: The importance of different types of elearning platform content.

to gain the same experience regardless of time and place of the course. Via e-learning, an unlimited number of participants can undergo the same training. By utilizing elearning, companies can offer additional education and the possibility of advancement to their employees, which is a significant motivator today for being loyal to the company that invests in their peoples' education. In crises, such as the current COVID-19, one can see how important it is to keep up with the technological advancement, especially in education. E-learning in companies should be planned to be in line with the strategic goals of the organization. The spread and further application of e-learning in business organizations will depend on meeting their expectations and proving the justification of the investment. This is possible with a planned, thorough, and continuous evaluation of the results of this type of teaching. Hence, it would be significant to continue research in this direction. For the future work, we plan to broaden the analysis by comparing the survey results coming from the different industries, different company sizes and different regions. We aim to obtain even better refinement of the existing appraisal of the e-learning, as well as the possible shortcomings of it. Also, we plan to include more companies in the survey, and further refine the questions themselves. We also plan to complement this research by investigating students' attitude towards e-learning, considering them as the future employees. We will specially target the students coming from technical universities who will eventually be the ones that will further develop e-learning.

Results of the conducted survey show that e-learning in business practice in the Republic of Croatia is still in the early phases of adoption. Despite the companies' opinion that they utilize e-learning in a daily basis, it is a matter of the day when this will become the reality. Furthermore, the results show that they consider investing in employee's education as an important factor for the companies' market competitiveness.

\section{References}

[1] A. S. Tsui, J. L. Pearce, L. W. Porter, and A. M. Tripoli (1997). "Alternative approaches to the employee-organization relationship: does investment in employees pay off?. Academy of Management Journal, Academy of management, vol. 40, no. 5, pp. 1089-1121. doi: 10.2307/256928. 
[2] D. Altig et al. (2020). "Economic uncertainty before and during the COVID-19 pandemic. "Journal of Public Economics, Elsevier, vol. 191. doi: 10.1016/j.jpubeco.2020.104274.

[3] A. Kapo, A. Mujkic, L. Turulja, and J. Kovačević (2020). "Continuous e-learning at the workplace: the passport for the future of knowledge". ITP, vol. ahead-of-print, no. ahead-of-print. doi: 10.1108/ITP-04-2020-0223.

[4] H. M. Selim (2007). "Critical success factors for elearning acceptance: Confirmatory factor models". Computers \& Education, Elsevier, vol. 49, no. 2, pp. 396-413. doi: 10.1016/j.compedu.2005.09.004.

[5] S. Negash, M. Whitman, A. Woszczynski, K. Hoganson, and H. Mattord, Eds (2008). Handbook of Distance Learning for Real-Time and Asynchronous Information Technology Education. IGI Global. doi: 10.4018/978-1-59904-964-9

[6] M. Puteh and S. Hussin (2007). "A comparative study of e-learning practices at Malaysian private universities", 1st International Malaysian Educational Technology Convention (2007)

[7] E. K. Kahiigi, L. Ekenberg, H. Hansson, F. F. T. Danielson, and M. Danielson (2008). "Exploring the e-Learning State of Art". Electronic Journal of $e$-Learning, Academic Conferences and Publishing International vol. 6, no. 2, p. 13.

[8] W. K. Horton (2000), "Designing Web-based training: how to teach anyone anything anywhere anytime". New York: Wiley

[9] M. Ćukušić and M. Jandrić (2012), "E-učenje: koncept i primjena". Zagreb: Školska knjiga

[10] H. M. W. Rasheed, Y. He, J. Khalid, H. M. U. Khizar, and S. Sharif (2020). "The relationship between e-learning and academic performance of students," Journal of Public Affairs, John Wiley \& Sons Ltd. doi: 10.1002/pa.2492.

[11] M. M. Škrtić, K. Horvatinčić, and A. Pisarović (2017). "E-learning from business processes aspect".

[12] Edward R. Kemery (2000), "Developing On-Line Collaboration, IGI Global doi:10.4018/978-1-878289-60-5.ch014

[13] K. Postolov, M. Magdinceva Sopova, and A. Janeska Iliev (2017). "E-learning in the hands of generation Y and Z". Business excellence, Faculty of Economic \& Business, vol. 11, no. 2, pp. 107119. doi: 10.22598/pi-be/2017.11.2.107.

[14] D. A. Cook (2007), "Web-based learning: pros, cons and controversies," Clinical Medicine, Royal College of Physicians, vol. 7, no. 1, pp. 37-42. doi: 10.7861/clinmedicine.7-1-37.

[15] J. L. Moore, C. Dickson-Deane, and K. Galyen, “eLearning, online learning, and distance learning environments: Are they the same?," The Internet and Higher Education, vol. 14, no. 2, pp. 129-135, Mar. 2011, doi: 10.1016/j.iheduc.2010.10.001.

[16] S. Ninoriya, P. M. Chawan, and B. B. Meshram (2011). "CMS, LMS and LCMS For eLearning". International journal of computer science,
International Journal of Computer Science Issues, vol. 8 , no. 2 , p. 5 .

[17] E. Dahlstrom, D. C. Brooks, and J. Bichsel (2014). "The Current Ecosystem of Learning Management Systems in Higher Education: Student, Faculty, and IT Perspectives". EDUCAUSE Annual Conference 2014, EDUCASE p. 27. doi: 10.13140/RG.2.1.3751.6005

[18] Y.-M. Cheng (2014). "Roles of interactivity and usage experience in e-learning acceptance: a longitudinal study". International Journal of Web Information Systems, Emerald Publishing Limited vol. 10 , no. 1 , pp. 2-23. doi: 10.1108/IJWIS-05-2013-0015.

[19] M. Di Ubaldo and I. Siedschlag (2020). "Investment in Knowledge-Based Capital and Productivity: Firm-Level Evidence from a Small Open Economy". Review of Income and Wealth, International Association for Research in Income and Wealth doi: 10.1111/roiw.12464. 